- Scholarly Societies and the science-promotion group Euroscience. The US National Academy of Sciences and the Royal Society, UK, issued a joint statement saying that the verdict "could lead to a situation in which scientists will be afraid to give expert opinion for fear of prosecution or reprisal". And the chief scientific adviser to the European Commission, Anne Glover, told Nature that she is concerned about the fallout from the case. "It may become more difficult to motivate scientists to advise on inherently uncertain issues," she says.

The verdict will set no legal precedent abroad. But there is a risk that L'Aquila could become an "informal precedent, in that it breaks down an aura of immunity surrounding science", says Sheila Jasanoff, who specializes on the intersection of science and the law at Harvard Kennedy School in Cambridge, Massachusetts. "People and lawyers may be more willing to sue when they feel bad advice has been given."

The day after the verdict, Luciano Maiani resigned as President of Italy's major risks commission, the expert panel that advises the national government on environmental hazards. Most of the convicted scientists had given their assessment of the seismic risk at L'Aquila as serving members of the committee. Maiani says that he was protesting not the verdict itself but the lack of legal protection for his committee.

Maiani, a physicist at the University of Rome, La Sapienza, and former directorgeneral of CERN, Europe's particle-physics facility near Geneva in Switzerland, says that, since taking up his post at the beginning of

this year, he has been asking the government to commit legal assistance to the committee members, as well as financial insurance in case of civil proceedings, but his requests have been refused. "This way it is impossible to give truly independent advice," he argues. "The obvious consequence is that scientists will tend to be more conservative in their advice, like some medical doctors who order too many tests and surgeries for fear of being sued. But this is not in society's best interest."

The full reasoning behind the verdict is not yet public, leaving some Italian legal experts baffled as to why the judge issued such a heavy sentence, making no

"Scientists are not elected, so it cannot be up to them to decide how to deal with an emergency." distinction between scientists in an advisory role and government officials entitled to take decisions and speak to the public. "Normally, the official who asks for expert advice remains legally responsible for the actions he then takes, unless the advice was wilfully and seriously wrong," says Stefano Rodotà, a legal specialist at La Sapienza and a former member of the Italian Parliament.

Glover says that the case underlines the importance of having clear rules on how scientific advice is given and used. "Before a scientist gives advice, it should be crystal clear to him or her what someone else is going to do with it", she says, but, ultimately, elected officials should be held responsible for decisions resulting from this process. "Scientists are not elected, so it cannot be up to them to decide how to deal with an emergency," Glover says.

Many scientists contacted by Nature agree that better legal protection, along with transparent guidelines about the obligations of science advisers, are long overdue in Italy. "The case resulted from the fact that the legal role of scientific advisers is still not well defined in Italy," says Mariachiara Tallacchini, who studies science-related legal issues at the Catholic University of Piacenza. "Countries such as the United Kingdom and the United States are more advanced in regulating science policy".

John Beddington, the UK chief scientific adviser, agrees. "I do not think such an outcome would be possible in the United Kingdom, unless the advice was demonstrably grossly negligent or wilfully malicious," he told Nature. "And in the case of civil proceedings, all advisers are indemnified by government." Similar protection is granted to science advisers in the United States, where seismologists advising national and state governments would be immune from such prosecution.

In Italy, there may be no time for reform before the next crisis. On 26 October, a magnitude-5.0 earthquake hit the Pollino region in the south of the country, where shocks have been going on for months - a situation very similar to that seen in L'Aquila in 2009. Maiani, who has not yet left the major risks commission, says that he and the other committee members will continue to serve during the current emergency. $\square$ SEE EDITORIAL P.7

ENERGY

\title{
Sahara solar plan loses its shine
}

\section{Siemens' decision to pull out of DESERTEC reignites doubts.}

\section{BY DEVIN POWELL}

$\mathrm{D}$ imming prospects for solar energy have caught up with a massive renewable-energy project planned for the Sahara Desert. By 2050, according to its backers, DESERTEC, a network of solar plants and other renewable sources scattered across North Africa and the Middle East, could generate more than 125 gigawatts of power that could be used locally or delivered to Europe through high-voltage direct-current cables beneath the Mediterranean Sea. But one of its major backers, Siemens, based in Munich, Germany, now says that it will leave Dii, the consortium trying to advance DESERTEC, by the end of the year.

"We see our part in Dii as done," says spokesman Torsten Wolf of Siemens, one of 13 founding partners of the consortium, which is also based in Munich.

Siemens also said that it will pull out of the solar-energy business altogether. Its decision was made in response to falling government subsidies for solar energy and a collapse in the price of solar equipment. But to DESERTEC'S critics, Siemens' exit also adds to doubts about the plan, which is expected to cost hundreds of billions of dollars. "DESERTEC is an ambitious attempt to do everything at once," says Jenny Chase, an analyst at Bloomberg New Energy
Finance in Zurich, Switzerland. "I think it's something that will be achieved organically, bit by bit, which will probably be cheaper, easier and achieve the same results."

DESERTEC's origins lie with retired particle physicist Gerhard Knies, who, after the 1986 Chernobyl nuclear disaster, had the idea of harvesting the Sahara's plentiful sunshine for energy. With the help of Prince El Hassan Bin Talal of Jordan, Knies brought together research institutes in Germany and North Africa, including some in Morocco, Algeria and Egypt, to start looking into the idea.

"For generating electricity from renewable, carbon-free sources, the economics makes more sense if we go to the Middle East and North Africa," says Ernst Rauch, Dii representative for the insurance company Munich $\mathrm{Re}$, one of the consortium's shareholders.

Siemens provided funds and technical expertise for preliminary studies, and in June, Dii published the result: a report that maps out the most cost-effective distribution of renewable-energy sources in 2050, based on simulations run by the Fraunhofer Institute for Systems and Innovation Research in Karlsruhe, Germany (see 'Power play').

Paul van Son, Dii's chief executive, says that 
